\title{
Analysing of Nonlinear Advanced Equation in Dynamic System
}

\author{
Esen Hanaç ${ }^{1 *}$ \\ 1* Adiyaman University, Faculty of Arts and Sciences, Departmant of Mathematics, Adiyaman, Turkey, (ORCID: 0000-0001-5561-7495), ehanac@adiyaman.edu.tr
}

(First received 8 October 2021 and in final form 6 December 2021)

(DOI: 10.31590/ejosat.1005848)

ATIF/REFERENCE: Hanaç, E. (2021). Analysing of Nonlinear Advanced Equation in Dynamic System. European Journal of Science and Technology, (31), 141-145.

\section{Abstract}

We mainly examine the type of the structure of the solutions of the following equation namely,

$$
u_{t}+k u u_{x}=u_{x x}+u^{2}(1-u),-\infty<x<\infty, t>0
$$

where $k \neq 0$ is a parameter occurrence in the long term by using dynamical system theory and exhibiting a phase-space analysis of its stable points. The critical points are identified depend on the solution of above equation in dynamic system. Then in parallel with the ciritical points eigenvalues and eigenvectors are determined and thus general solutions are written by depending on those found eigenvalues and eigenvectors. Thus, the structure of the critical points can be named in the phase -space. After some minor calculations are done, from one equilibrium point that enhancing from 0 to decreasing to 1 into the other and thus heteroclinic trajectory is demonstrated that supports the travelling wave solution to the equation. Then all points are indicated depending on properties of the structure of eigenvalues of the critical points in phase-space by using a generated matlab implementation. The result of the our work illustrates that the equation can confirm shock-wave solutions

Keywords: Phase-space analysis, Nonlinear advanced equation, Shock-wave solutions.

\section{Dinamik Sistemde İleri Nonlineer Denklemin Analizi}

$\ddot{\mathbf{O} z}$

Aşağıdaki denklemin

$$
u_{t}+k u u_{x}=u_{x x}+u^{2}(1-u),-\infty<x<\infty, t>0
$$

$k \neq 0$ bir parametre, sonuçlar yapısını dinamik sistemi ve sabit noktaların faz-uzay analizlerini kullanarak, uzun zamandaki oluşumunu inceliyoruz. Dinamik sistemde yukarıdaki denklemin çözümüne bağlı olarak kritik noktalar belirlenir. Daha sonra kritik noktalara paralel olarak özdeğerler ve özvektörler belirlenir ve böylece bulunan özdeğerler ve özvektörlere bağlı olarak genel çözümler yazılır. Böylece kritik noktaların yapısı faz uzayında isimlendirilebilir. Bazı küçük hesaplamalar yapıldıktan sonra, 0'dan 1'e artan bir denge noktasından diğerine doğru artan ve böylece heteroclinic yörüngenin denkleme giden dalga çözümünü desteklediği gösterilmiştir. Daha sonra üretilen bir matlab uygulaması kullanılarak faz uzayındaki kritik noktaların özdeğer yapısının özelliklerine bağlı olarak tüm noktalar belirtilir. Çalışmamızın sonucu, denklemin şok dalgası çözümlerini doğrulayabildiğini göstermektedir.

Anahtar Kelimeler: Faz-uzay analizi, İleri nonlineer denklem, Dalga çözümleri.

\footnotetext{
* Corresponding Author: ehanac@adiyaman.edu.tr
} 


\section{Introduction}

It is well known that obtaining analytical solutions of nonlinear partial differential equations has a significant role to define physical phenomena which are rising in several areas such as physics, biology, chemistry and engineering (Cross and Hohenberg, 1993; Dee and Langer, 1983; Bramson, 1983; Burgers, 1939; Burgers, 1940; Burgers, 1975; Van Saarloos, 2003). Many different methods have been applied to determine the analytical wave solutions to nonlinear equations for many years science (Behzadi and Araghi, 2011; Bramson, 1983; Burgers, 1939; Burgers, 1940; Burgers, 1975; Van Saarloos, 2003 ). Numerous nonlinear equations have an extensive area of applications in fluid mechanics, chemical and plasma physics and so on. One of those equations is the generalized Burgers-Fisher equation,

$$
u_{t}+\delta u^{n} u_{x}=\varepsilon u_{x x}+\vartheta u\left(1-u^{n}\right)
$$

where $\delta, \varepsilon, \vartheta$ in real number and $n>0$ is constant. Some analytic accurate travelling wave solutions of the equation (1) have been demonstrated by applying different methods. When $\delta$ is counted as 0 the equation (1) is reduced to the Fisher-KPP equation which has been studied by many authors science (Behzadi and Araghi, 2011; Bramson, 1983; Burgers, 1939; Burgers, 1940; Burgers, 1975; Van Saarloos, 2003 ). When $\vartheta$ is counted as 0 the equation (1) is reduced to the generalized Burgers equation. Many scientists in different area have given an enormous effort to the generalized Burgers equation to find the exact travelling wave solutions of it through the years due to its value in science. Despite of the methods used in those equations to solve travelling wave solutions of them the dynamical attitude of the ordinary differential equation forms of the equation (1) or reduced forms of (1) have not been taken as consideration. In this paper, the dynamic system of a modified form of the equation (1) given as

$$
u_{t}+k u u_{x}=u_{x x}+u^{2}(1-u)
$$

where $k \neq 0$ is a parameter, has been considered. We hope to find a travelling wave solution occurance which is corresponded by a heteroclinic orbit in phase space. Therefore we examine the phase plane analysis of the dynamic system of ode form the equation (2) and give exact solution for the equation (2) in the section 2 . In the latter section, we analyse the dynamical system of the ode form of the equation (2) numerically and represent numerical solution and exact solution in same graph. In the last section we conclude our work and give a summary of our results.

\section{Dynamical system}

In this section we first substitute the transformation given below into the equation (2)

$$
s=x-c t \quad u=U(s)
$$

where $c$ is the wave speed and we get that

$$
-c U_{s}+k U U_{s}=U_{s s}+U^{2}(1-U) .
$$

The dynamical system of the equation (4) is obtained on writing $U_{s}=V$ and we have

$$
\begin{aligned}
& U_{s}=V \\
& V_{s}=-c V+k U V-U^{2}(1-U) .
\end{aligned}
$$

The dynamical system (5) has two equilibrium points at $\mathrm{P}:(0,0)$ and $\mathrm{R}:(1,0)$. We require a monotone solution in $0 \leq U \leq 1$ with $U_{s}(s) \leq 0$. We next classify the equilibrium points by linearization. According to the theory of the dynamic system, if eigenvalues of the equilibrium point are both less than 0 , the equilibrium point is stable node; If eigenvalues of the equilibrium point are both greater than 0 , the equilibrium point is unstable node; If eigenvalues of the equilibrium point have different sign, the equilibrium point is saddle node. We first consider the equilibrium point $\mathrm{P}:(0,0)$. The associated linear system and the jacobian matrix of the system are given by

$$
\begin{aligned}
& U_{s}=V \\
& V_{s}=-c V-U^{2} \\
& A^{+}=\left[\begin{array}{cc}
0 & 1 \\
-2 U & -c
\end{array}\right] .
\end{aligned}
$$

Eigenvalues of the jacobian matrix $A^{+}$and associated eigenvectors are given by

$$
\begin{array}{ll}
\rho_{1}=0 & \rho_{2}=-c, \\
v_{1}=\left(\begin{array}{l}
1 \\
0
\end{array}\right) & v_{2}=\left(\begin{array}{l}
1 \\
c
\end{array}\right) .
\end{array}
$$

Because of one eigenvalue is zero the other one determine the model of node in phase plane. So we consider the eigenvalue $-c$ which decays to 0 and shows stable node. Figure 1 displays the $(\mathrm{U}, \mathrm{V})$ phase plane in the neigbourhood of the equilibrium point $\mathrm{P}:(0,0)$. The stable node is clearly displayed on the figure.

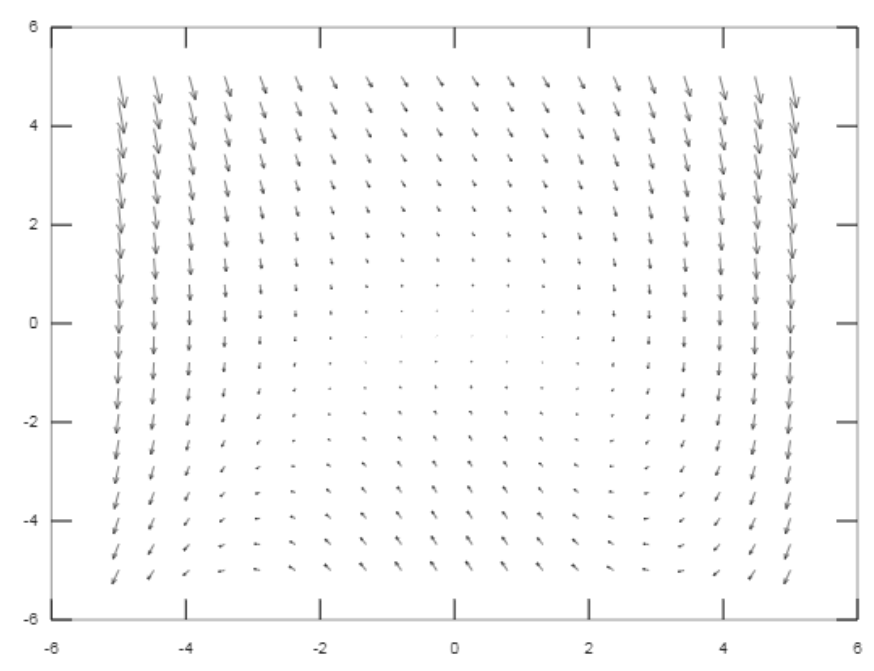


Figure1. Vector flow for the system (6)

We next consider the equilibrium point R:(1,0). On writing $\breve{U}=$ $U-1$ and $\breve{V}=V$ the associated linear system of the equilibrium point $\mathrm{R}:(1,0)$ and the jacobian matrix of the system are obtained

$$
\begin{aligned}
& \breve{U}^{\prime}=V \\
& \breve{V}^{\prime}=\breve{U}+(k-c) \check{V} \\
& A=\left[\begin{array}{cc}
0 & 1 \\
1 & k-c
\end{array}\right] .
\end{aligned}
$$

Eigenvalues of $A$ and associated eigenvectors are given by

$$
\begin{gathered}
p_{ \pm}=\frac{(k-c) \pm \sqrt{(k-c)^{2}+4}}{2}, \\
v_{ \pm}=\left(\begin{array}{c}
1 \\
\rho_{ \pm}
\end{array}\right) .
\end{gathered}
$$

Now since $\rho_{+}>0>p_{-}$the point R:(1,0) is a saddle point. The solution of our modified Burger-Fisher equation germinate to shock wave in three specific values of $c$. The first case while $c=k$ 2 with $k>2$ then the fixed point $\mathrm{R}:(1,0)$ exhibits saddle node. The latter case is while $c=k+2$ with $k>0$ then the fixed point $\mathrm{R}:(1,0)$ exhibits saddle node too. The last one is when $c=\frac{k}{2}+$ $\frac{2}{k}$ with $k \geq 2$ and again the fixed point $\mathrm{R}:(1,0)$ exhibits saddle node. Therefore, the Linearization Theorem indicates that point $\mathrm{R}:(1,0)$ is a saddle point for nonlinear system. Figure 2 displays the $(\mathrm{U}, \mathrm{V})$ phase plane in the neigbourhood of the equilibrium point $\mathrm{R}:(1,0)$. The unstable manifold entering the region where $\mathrm{V}<0$ is clearly displayed in the figure.

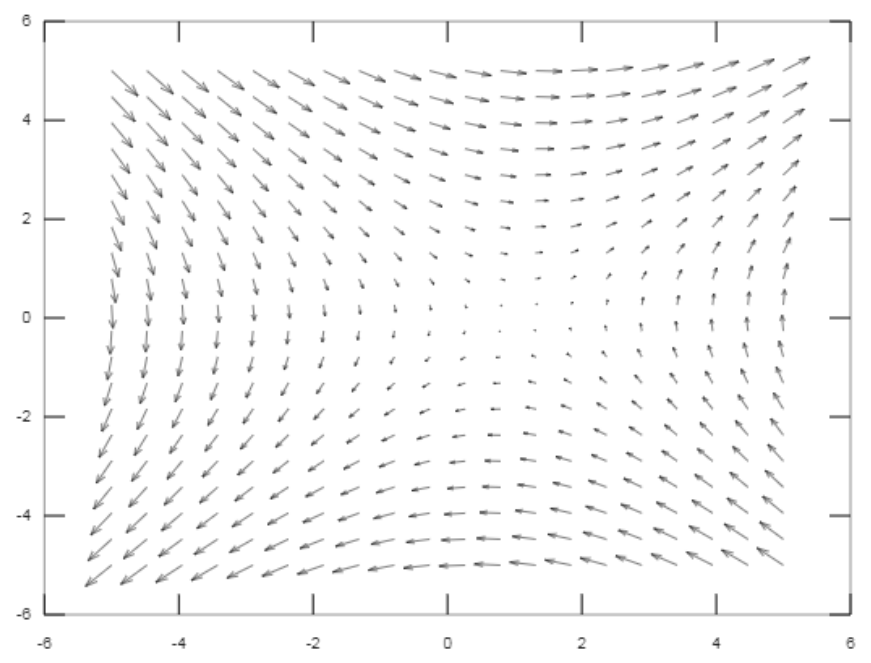

Figure2. Vector flow for the system (7)

We note from linear system (5) $\frac{d}{d c}\left(\frac{d V}{d U}\right)=-1$ the phase plane rotates clockwise for increasing $c$. We further note that a close exact solution of the system (5) exists and is given by

$$
U(s)=1-\frac{2}{1+B e^{-(1+2 \sqrt{2}) z}}
$$

$$
U(s) \sim\left\{\begin{array}{l}
\sim 1-\frac{1}{B} e^{c z} \quad z \rightarrow-\infty \\
\sim B e^{-c z} \quad z \rightarrow \infty
\end{array}\right.
$$

where $B$ is constant and when $c=k-2, k+2$ and $\frac{k}{2}+\frac{2}{k}$. All from these solutions the phase path is determined for $s=x-c t$ joining the fixed points $\mathrm{P}:(0,0)$ and $\mathrm{R}:(1,0)$ and that gives a heteroclinic connection between the equilibrium points for these three chosen wave speed $c$.

\section{Parabolic Method}

We practice numeric techniques for clarifying this model and comparing its closed form solution with shock wave solution of the equation (2). We practise parabolic method to get numeric explication of the equation (2). For further details about the method the references (Griffiths and Schiesser, 2009; Griffiths and Schiesser, 2010; Landejuela, 2011; Hanaç, 2021) is cited to read for who is interested in. After some computations we get the numeric style of equation like,

$$
\begin{aligned}
U_{j}^{n+1}= & U_{j}^{n}+\Delta t\left(\frac{U_{j+1}^{n}-2 U_{j}^{n}+U_{j-1}^{n}}{\Delta x^{2}}\right) \\
& +k \frac{U_{j-\frac{1}{2}}^{n}-U_{j+1 / 2}^{n}}{\Delta x}+\varepsilon_{j}^{n}(x)\left(1-U_{j}^{n}\right)=0
\end{aligned}
$$

where $\varepsilon_{j}^{n}(x)$ refers to as $u^{2}(x)$. In Figure 3 exact solutions to the Burger Fishers model exhibits for $\mathrm{c}$ which is chosen specifically.

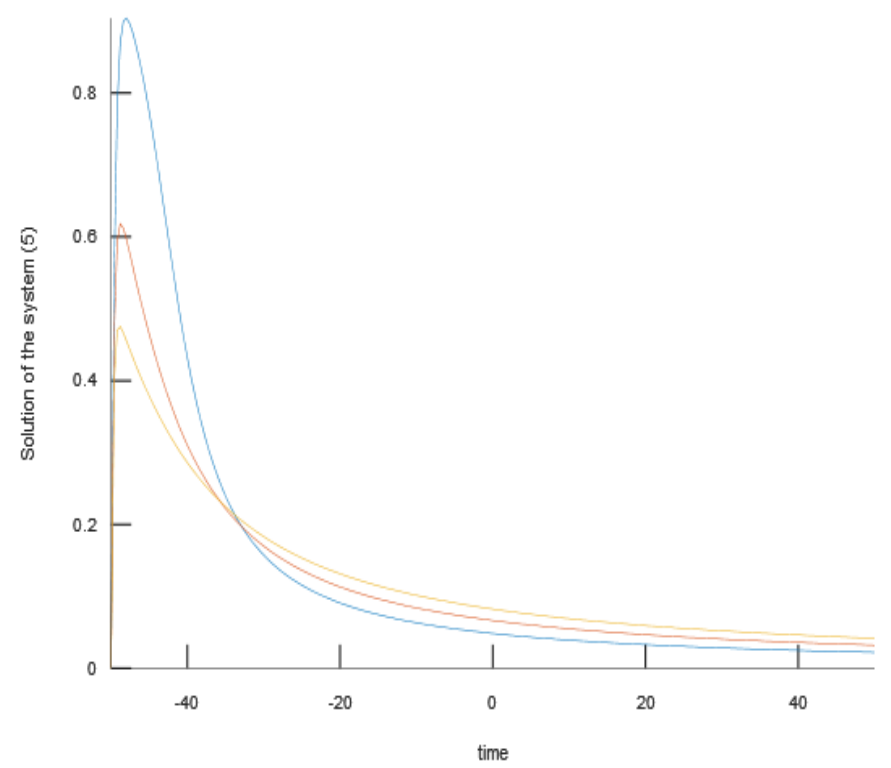

Figure3. Exact solutions for dissimilar values of $c$ is shown in the physical plane. Figure also displays the shock wave portraits $U(s)$ that encounter (8). 
We portray the numerical finding out of the equation (2) with chosing $N^{*}$ grid point equals to $250, \Delta t=.5$ and the exact solution (8) for the wave speed $c=k-2$ with $k>2$. In Figure 4 the shock wave solution of the equation(2) with waving accelerate $c=k-2$ is observed to grow quickly as $t \rightarrow \infty$ and the red line is represented by the exact solution and the overlap one that blue line is represented by the numeric result, sustains that time dependant solution gets close form of the exact solution fairly rapid.

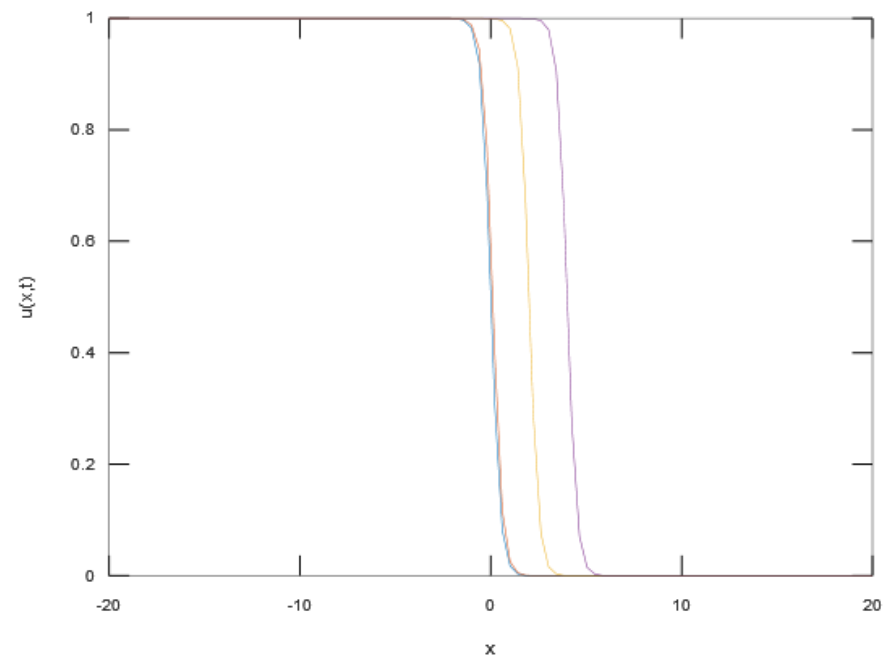

Figure4. Chart of exact solution (red line) and the numerical solutions of the equation (2) at times $t=0,2,4$.

Besides in the Figure 4 we portray the numerical finding out of the equation (2) with chosing $N^{*}$ grid point equals to $250, \Delta t=$ .5 and the exact solution (8) for the wave speed $c=k+2$ and $c=\frac{k}{2}+$ $\frac{2}{k}$ respectively. In Figure 5 and 6 the shock wave solution of the equation(2) with waving accelerate $c=k+2$ and $c=\frac{k}{2}+\frac{2}{k}$ respectively reveal intensly good agreement between exact solutions and numeric results.

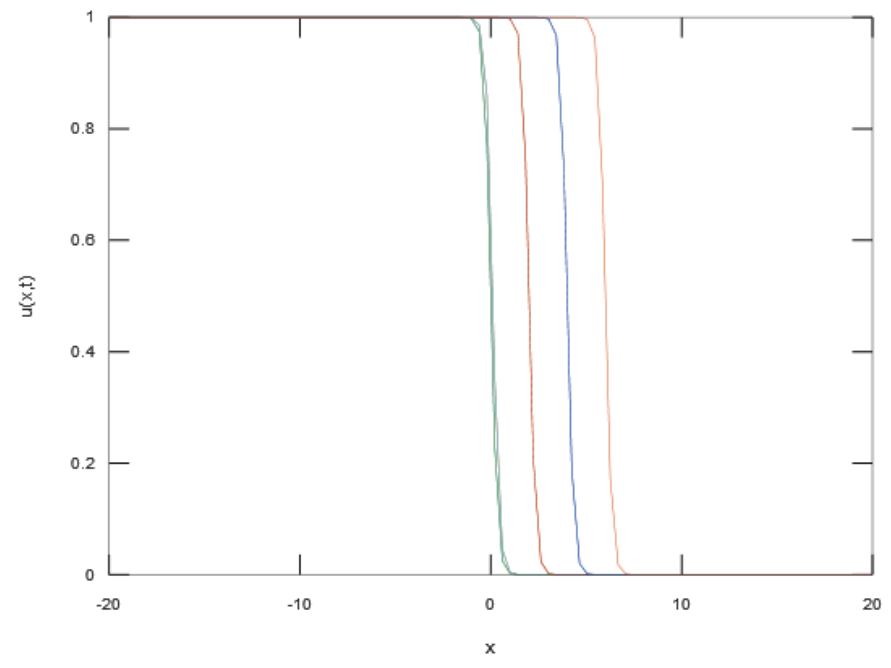

Figure5. Chart of exact solution (green line) and the numerical solutions of the equation (2) at times $t=0,2,4,6$.

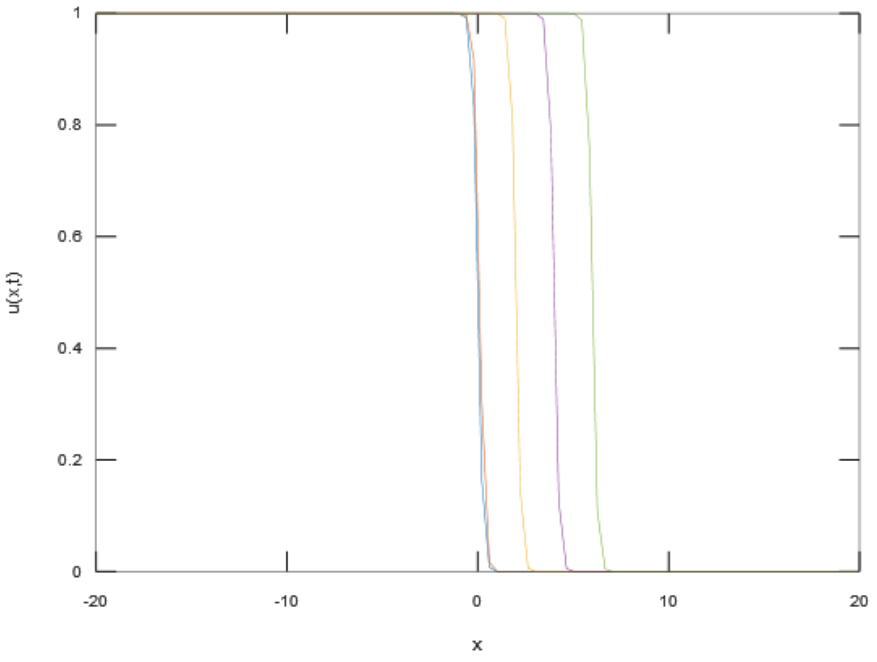

Figure6. Chart of closed form of exact solution (red line) and the numerical solutions of the equation (2) at times $t=$ $0,2,4,6$.

\section{Conclusion}

In this paper, we search the Burger Fisher equation with the modified advection part and parameter $k \neq 0$ (2) in dynamic theory. We review the dynamic behaviour of shock wave solutions of the equation (2) applying linearizaton theorem. We reach phase path and indicate joinnig orbit occurance which provides soliton solutions. Lastly, we apply parabolic method to get numerical solutions of the equation (2) and compare with exact solution in same distance $\mathrm{x}$ with time intervals for waving accelerate $c=k-2$ $c=k+2$ and $c=\frac{k}{2}+\frac{2}{k}$ respectively. The equation with the modified advection part and parameter $k \neq 0$ has various impressive properties. The modified advection part and parameter $k \neq 0$ mathematical model form has shock wave solutions for three specific value of $c$. Mathematical model of the modified form ensures a simple phsical version, for an exact solution with $c=$ $k-2$, with $c$ less than 2 on the pretense of unpyhsical (Canosa, 1973;Edelstein-Keshet, 2005;Fisher, 1937; Kolmogorov et al, 1937; Kot, 2003; Murray, 2002 ).

\section{References}

Behzadi, S.S and Araghi, M.A.F., (2011). Numerical Solution for Solving Burgers-Fisher Eguation by Using Iterative Methods.Mathematical and Computational Applications16, 443-455. https://doi.org/10.3390/mca16020443

Bramson, M.D., (1983). Convergence of solutions of the Kolmogorov equation to travellingwaves. Mem. Amer. Math. Soc.44. ISBN: 978-1-4704-0695-0

Burgers, J.M., (1939). Mathematical examples illustrating relations occurring in the theory of turbulent fluid motion.Verh. Nederl. Akad. Wetensch. Afd. Natuurk.17, 153. https://www.dwc.knaw.nl/DL/publications/PU00011461.pdf Burgers, J.M., (1940). Application of a model system to illustrate some points of the statistical theory of free turbulence. Proc. Kon. Nederl. Akad. Wetensch.43, 2-12.

Burgers, J.M., (1975). The Nonlinear Diffusion Equation. D. Reidel Publishing Company, Dordrecht, Holland. 
Fisher, RA., (1937). The wave of advance of advantageous genes.
Annals
of
Eugenics.
7
355-369.

https://doi.org/10.1111/j.1469-1809.1937.tb02153.x

Griffiths, G., Schiesser, W. E., (2009). A Compendium of Partial Differential EquationModels. Cambridge University Press doi:10.1017/CBO9780511576270

Griffiths, G., Schiesser, W. E., (2010). Travelling Wave Analysis of Partial DifferentialEquations. Academic Press. ISBN: 978$0-12-384652-5$

Hanaç, E. (2021). The Stability of A modified form of Reaction Diffusion Equation in Phase Plane. https://doi.org/10.31590/ejosat.920615

Kolmogorov, AN, Petrovskii, PG, Piskunov, NS. (1937). A study of the diffusion equation with increase in the amount of substance, and its application to a biological problem. Moscow

University Mathematics Bulletin. 1 1-26.

Kot, M., (2003). Elements of Mathematical Ecology. Camridge University Press, Cambridge. https://doi.org/10.1017/CBO9780511608520

Landejuela, M., (2011). Burgers Equation. BCAM Internship report: Basque Center forApplied Mathematics.

McKean, H.P., (1975) . Application of Brownian motion to the equation of Kolmogorov-Petrovskii-Piskunov. Comm. Pure Appl. Math.28, 323-331. https://doi.org/10.1002/cpa.3160280302

Murray, JD. (2002). Mathematical Biology I: An Introduction. Third edition, Springer, New York. ISBN 978-0-387-224374

Van Saarloos, W., (2003). Front propagation into unstable states. Phys. Rep.386, 29-222. 